Brit. J. industr. Med., 1961, 18, 103.

\title{
CARBON PNEUMOCONIOSIS
}

\author{
BY \\ A. A. MILLER and F. RAMSDEN \\ From the Group Laboratory, Royal Infirmary, Preston
}

(RECEIVED FOR PUBLICATION MAY 20, 1960)

\begin{abstract}
The occurrence of carbon pneumoconiosis in rubber-factory workers is unusual: the case reported here was discovered in a routine post-mortem examination. The report includes the clinical, radiological, morbid anatomical, and histological findings on a man who had worked in the carbon black store of a rubber works for a continuous period of 21 years, followed by 11 years in the calender department of the same factory. At the age of 65 years the man was retired on the grounds of age and indifferent health: he collapsed and died soon afterwards.

The medical history of severe cough with expectoration suggested that he may have had pulmonary tuberculosis in earlier life and some supporting evidence of this infection was found in that his wife contracted this disease after marriage and subsequently died from tuberculosis.

The appearances of massive fibrosis in the upper lobes of the lungs suggested that the combined action of carbon black and tuberculosis had produced an "infective" type of pneumoconiosis: in the lower lobes there was far less fibrosis and the appearances were those of simple pneumoconiosis. In addition to the fibrosis the lungs showed nodules of black dust with severe perifocal emphysema. Electron microscopy of the lung dust showed two distinct components and they were similar to samples of channel and thermal blacks which were the main types of carbon used in the factory.

This case is an example of pneumoconiosis due to virtually non-siliceous carbon and illustrates that prolonged exposure to heavy dust concentration produces such lesions as described in this paper.
\end{abstract}

Most of the published work on carbon pneumoconiosis is concerned with radiological appearances (Lochtkemper and Teleky, 1932). Gärtner and Brauss (1951) described lung changes in soot workers which were those of simple pneumoconiosis: in none of these cases was there evidence of massive fibrosis.

Koelsch (1952) described a condition of " pure carbon lung" which he found in electrode workers who had handled a pure form of carbon with very little silica contamination. He called it an advanced stage of carbon pneumoconiosis and not silicosis. Radiologically there were nodulation and conglomerate shadows with massive fibrosis. With so low a silicic acid content in the dust he was unable to explain the radiological findings, which were similar to soot workers' "silicosis" of the second and third degrees. In this paper, Hollmann is quoted as saying that carbon electrode workers are in danger of silicosis.

Meiklejohn (1957) studied the radiological changes in a group of carbon black workers and found the reticulation of simple pneumoconiosis: in a second group handling carbon with a small amount of mineral impurity, one man showed the radiological appearances of pneumoconiosis with fibrosis (category 2A) (International Labour Organization, 1953).

Vaccarrezza (1958) described lung changes in a man who had been shovelling charcoal for several years and Watson (in Gough, 1959) described changes in the lungs of a carbon electrode worker.

In all these papers, excepting that of Watson, the evidence is entirely radiological: histological examination could not be made as the workers were alive and had not undergone surgery to the lungs.

From the findings of these and other workers it appears that pneumoconiosis can be caused by carbon and other relatively inert dusts containing little or no siliceous material. Even if the small amount of silica present does cause fibrosis, the pathology is so different from that seen in pure silicosis that it is best not to use the word silicosis in describing it (Fletcher, 1952).

Amongst the forms of occupational lung disease carbon pneumoconiosis, other than in coal-miners, is fairly uncommon: in a rubber-factory worker it must be very unusual (Meiklejohn, 1956). The 
following case which was discovered at a routine necropsy performed for H.M. Coroner, appears to be an example of "pure carbon" pneumoconiosis.

\section{Case Report}

Occupational History.-From the age of 17 , until his retirement at the age of 65 , A.W. worked almost continuously in rubber factories in one town: the only breaks were two years' military service in the 1914-1918 war and almost two years' unemployment soon after the war. In 1959 he retired and a few months later he died.

For a continuous period of 21 years (1927-1948) he worked in the carbon black store where the main ventilation was a doorway which opened on to a partially covered alley way.

The carbon, in $50 \mathrm{lb}$. bags, was stacked at the back of the store and from this pile the workman dragged the bags across the floor, opened them, and poured the carbon into tubs placed on a scale until the correct weight was obtained. Even with pelletized carbon this procedure creates thick clouds of dust; before pelletization the amount of carbon in the air must have been appalling.

When the correct amount of carbon has been weighed out, the tubs are wheeled across the alley and placed on a conveyer system which leads to the mixer: whilst on the conveyer various other fillers such as zinc oxide are added. In the mixing machine the fillers and molten rubber are mechanically blended.

During the 1939-1945 war years A.W. regularly worked in the carbon black store for up to 54 hours a week. During the whole of his time in this store he never wore a mask nor took any precautions to avoid contamination. The carbon black filled his clothes and soiled his skin to such an extent that he was strongly discouraged from sitting in a bus or train when travelling to and from his work. Attempts to remove the dust from his skin were relatively unsuccessful: he used various proprietary preparations and visited the local baths weekly, but with little improvement. He went occasionally to another town to have a Turkish bath and the results were more satisfactory.

He paid little heed to objections from his wife and others about his personal appearance. He enjoyed his work in the "blacking shop" because of the extra pay and relative independence: advice about contamination was disregarded. At night he slept in a separate room; his wife made him a special hood for his head and a long type of nightdress for his body in order to reduce soiling the bed clothes.

From 1948-1959 he worked as a sweeper in the calender department where rubber is coated on to a fabric base in the production of conveyor belting and similar items. The air in the calender section contained traces of carbon black and also talcum powder which was used to prevent the slabs of rubber adhering: there were also traces of sulphur, zinc, and magnesium oxides in this atmosphere but the amounts were very small. He never worked in the talc section.
Medical History.-A.W. had a persistent hard cough, with a small amount of black sputum for about 30 years and at times he was "short of breath" in the night. He married in 1928 and at that time his wife was healthy. Three years later she developed chest symptoms. In 1940 tuberculosis of the spine was diagnosed and treated. She died in 1942.

In 1949, when he had an attack of dermatitis, he was moved from the carbon store to the calender department and employed as a sweeper. In 1956 he began to notice mild exertional dyspnoea which slowly increased, and the cough with sputum became more marked.

A chest radiograph was taken in 1956 and again in 1958 when the mass miniature radiography unit visited the factory. These radiographs showed generalized reticular appearances throughout both lung fields with increased lung markings and fibrosis, especially in both upper zones.

Standard sized radiographs were taken and showed that in the left upper zone the fibrous mass was displaced downwards to the hilum by what appeared to be emphysematous bullae or pneumothorax, probably the former. The massive shadows were connected to the hilum and the apex by trabeculae and fibrous strands which are often seen in cases of tuberculosis and are due to thickened and fibrogenic bronchi. There was no evidence of active tubercle (Fig. 1).

Professor A. L. Cochrane reviewed the films and reported progressive, massive fibrosis of both upper zones.

He was examined by Dr. Geake (Consultant Chest Physician) in 1958. His general condition was good, his chest movement was poor and there was no added sound or localizing abnormal sign. The sputum was not examined bacteriologically. Dr. Geake considered that the radiological appearances were due to some form of pneumoconiosis and suggested the possibility of harmful dust to which the patient might have been exposed in the rubber factory.

Further examination of his past history revealed attacks of dizziness and fainting. On two occasions whilst on holiday, once in 1955 and again in 1958, he collapsed and was ill for a few weeks. His recovery was fairly rapid and he resumed his normal work in the factory. In 1959, whilst at work, he had another fainting attack and fell downstairs but did not sustain serious injury. After this the management suggested that he should retire.

After his retirement in February 1959 his cough became worse and he continued to expectorate a moderate amount of black sputum. His general condition was moderately good until about a week before his death (April 1959), when he seemed to lose interest in things and did not feel so well. He was found dead in his home, having collapsed whilst working in the kitchen.

Necropsy.-The only notable external feature was the generalized blackening of the skin. This was most marked on the palms of the hands and could not be washed off.

In the upper respiratory passages the mucosa was congested but not pigmented. Both lungs were enlarged, each weighing over 610 g.: they were intensely black 
and large whitish emphysematous bullae were present at the apices and along the anterior margins. The upper lobes were severely contracted and fibrosed, the apical portions being largely replaced by enormous emphysematous bullae (Fig. 2). The posterior part of the upper lobes and the apices were firmly adherent to the chest wall and the interlobar fissures were closed by adhesions. The visceral pleura, covering most of the upper lobes, was thickened and, together with the remaining visceral pleura, showed peculiar speckled black and grey appearances with large, soft black velvety patches.

On palpation there were numerous, small, firm nodules scattered irregularly throughout the upper lobes; a smaller number were present in the lower lobes. There were no discrete palpable fibrous masses in any part of the lung substance.

On sectioning the lungs, the most striking feature was the copious oozing of black mucinous material from the cut ends of the bronchi and bronchioles: this secretion adhered to instruments, hands, and working surfaces. Two of the large emphysematous bullae at the left apex had penetrated the lung substance producing cavities measuring $7 \times 3 \mathrm{~cm}$. and $5 \times 4 \mathrm{~cm}$.; their walls were

FIG. 1.-The chest radiograph shows complicated pneumoconiosis with massive fibrosis in the upper zones and emphysematous bullae at the apex.

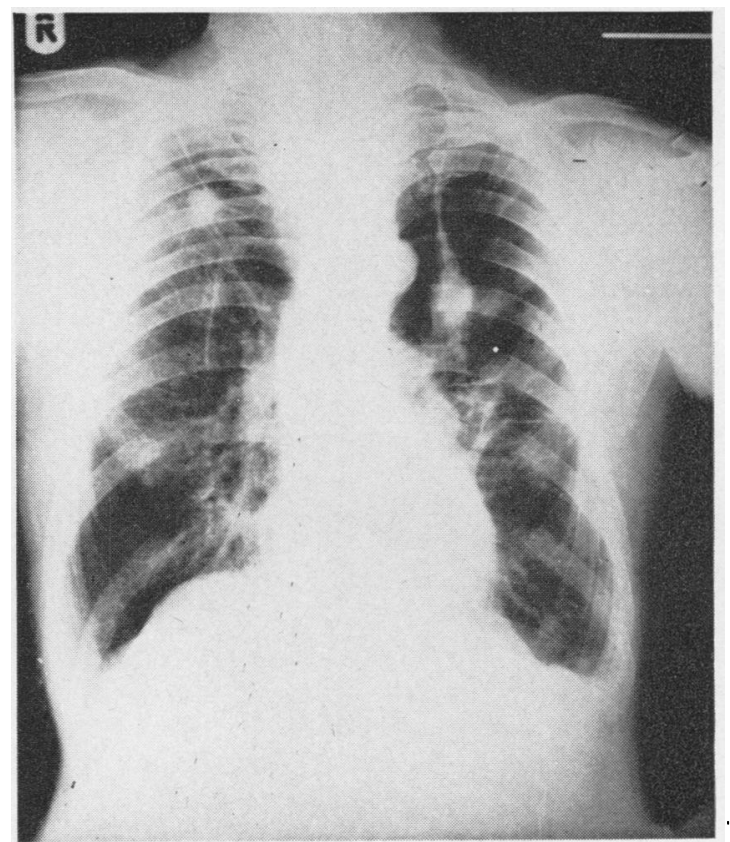

Fig. 2.-Formalin-fixed left lung. This photograph is a light print in order to show detail. The lungs were much darker than the print suggests: they showed severely scarred and contracted upper lobes with large apical emphysematous bullae. 


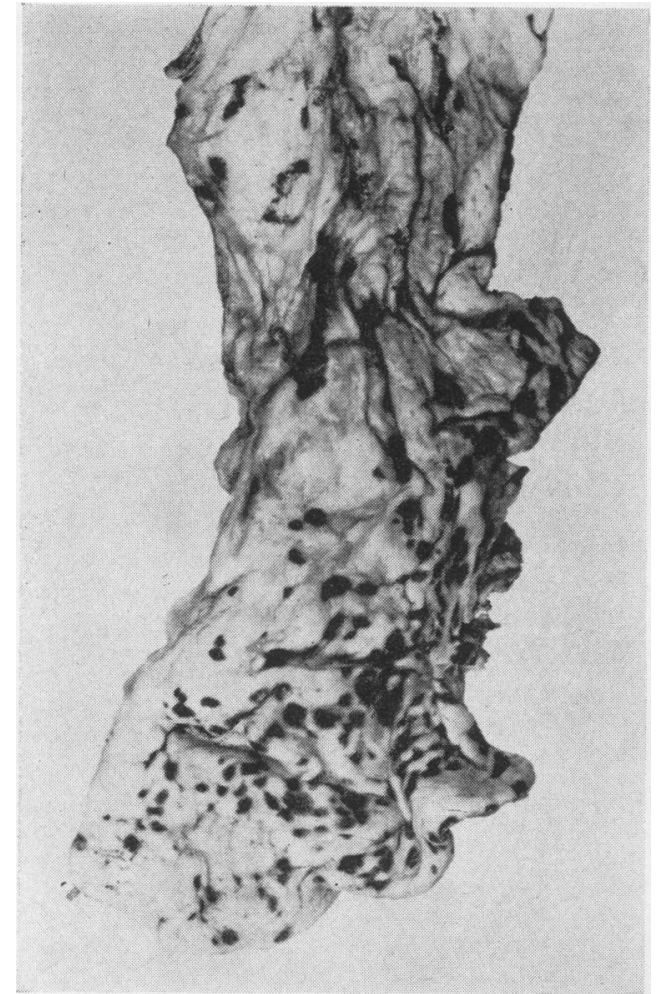

FIG. 3.-A piece of stomach wall showing the mucosa speckled with deposits of carbon black $(\times 2)$.

black, ragged, and contained tendrils and strands of necrotic tissue. A smaller bulla at the right apex showed similar appearances. In the lower part of both upper lobes there was fibrosis with thick walled bronchi: enlarged pigmented lymph nodes were found at the hilum. In both lower lobes the cut surfaces were intensely black, the lung substance largely obscured by sticky black material: there were numerous small, poorly defined, black nodules (not exceeding $5 \mathrm{~mm}$. in diameter) surrounded by focal emphysema. Some of the larger nodules showed a central cavity containing black sludge. There was also slight generalized emphysema.

The remarkable features were the intense blackness of the lungs, the white ballooned appearances of the apical bullae associated with cavitation of the upper lobes, marked fibrosis of the upper lobes, the small pneumoconiotic nodules distributed irregularly throughout the lung substance and the slightly generalized emphysematous character of the lungs. There was no evidence of tuberculosis.

It was subsequently noted that the intense blackness of the lungs remained unaltered after they had been immersed in several changes of formalin; the fixative was changed to inky black fluid with considerable tarry black sediment.

Other abnormalities which were probably related to the deceased's occupation were found in the lower end of the oesophagus and the cardiac end of the stomach (Fig. 3). The mucosa was speckled with spherical and irregularly outlined collections of black pigment measuring from about 2 to $6 \mathrm{~mm}$. in diameter; there was one elliptical area measuring $15 \times 5 \mathrm{~mm}$. These pigmented patches were firmly adherent to the mucosa and resisted attempts to remove them by washing and rubbing. The pigment was similar to that found on the serous surfaces of the lungs.

The heart showed mitral stenosis due to healed rheumatic endocarditis: there was slight cor pulmonale: the main coronary arteries were partly occluded by atheroma. The kidneys showed granularity and arteriosclerotic changes. The brain showed marked internal hydrocephalus.

The cause of death was bacterial and rheumatic endocarditis and pneumoconiosis.

\section{Histology.}

Lungs: The general features were those of collagenous fibrosis with small fibrous nodules; well-marked focal and slight general emphysema (Fig. 4). The mucosa of the bronchi and bronchioles showed partial atrophy of the epithelium and dense infiltration with black pigment: their lumen contained desquamated epithelium, clumps of black pigment, and dust-laden phagocytes. There were moderate amounts of inflammatory exudate but bronchopneumonia was not seen.

Typical reticulin fibrosis was seen around many of the bronchioles but the predominant appearance was linear and radial collagenous fibrosis with dense pigmentation (Fig. 5). In many areas the heavy dust infiltration completely obscured the collagenous tissue.

Around bronchioles and blood vessels there were pigmented nodules, singly and in clusters, which had caused marked collagenous reaction. In the upper parts of the lungs the nodules tended to coalesce to form larger nodules (Fig. 6). The smaller type of nodule measured up to $5 \mathrm{~mm}$. in diameter and was surrounded by focal emphysema. The larger nodules, measuring 5-10 mm. in diameter, consisted of densely pigmented, whorled hyaline fibres showing some resemblance to silicotic nodules; some of these larger ones showed central liquefaction (Fig. 7), the cavity containing a sludge of pigment, leucocytes, and necrotic tissue; they were not the typical laminated type seen in classical silicosis but suggested the "infective nodules" of "complicated" pneumoconiosis described by Gough (1947); the appearances suggested progressive massive fibrosis.

The wall of the large emphysematous cavity in the left upper lobe showed linear and radial fibrosis, the tissue being obscured in parts by the dense pigmentation. Deeper parts of this region, which extended almost to the hilum, contained thick fibrous strands in which residual fragments of bronchial walls and blood vessels were seen.

Lymph nodes in the parabronchial tissue showed fibrosis with pigmented areas. In the lower lobes the appearances were mainly those of simple pneumoconiosis (Figs. 8, 9); there were areas of collagenous thickening of alveolar walls, many of which had become confluent 


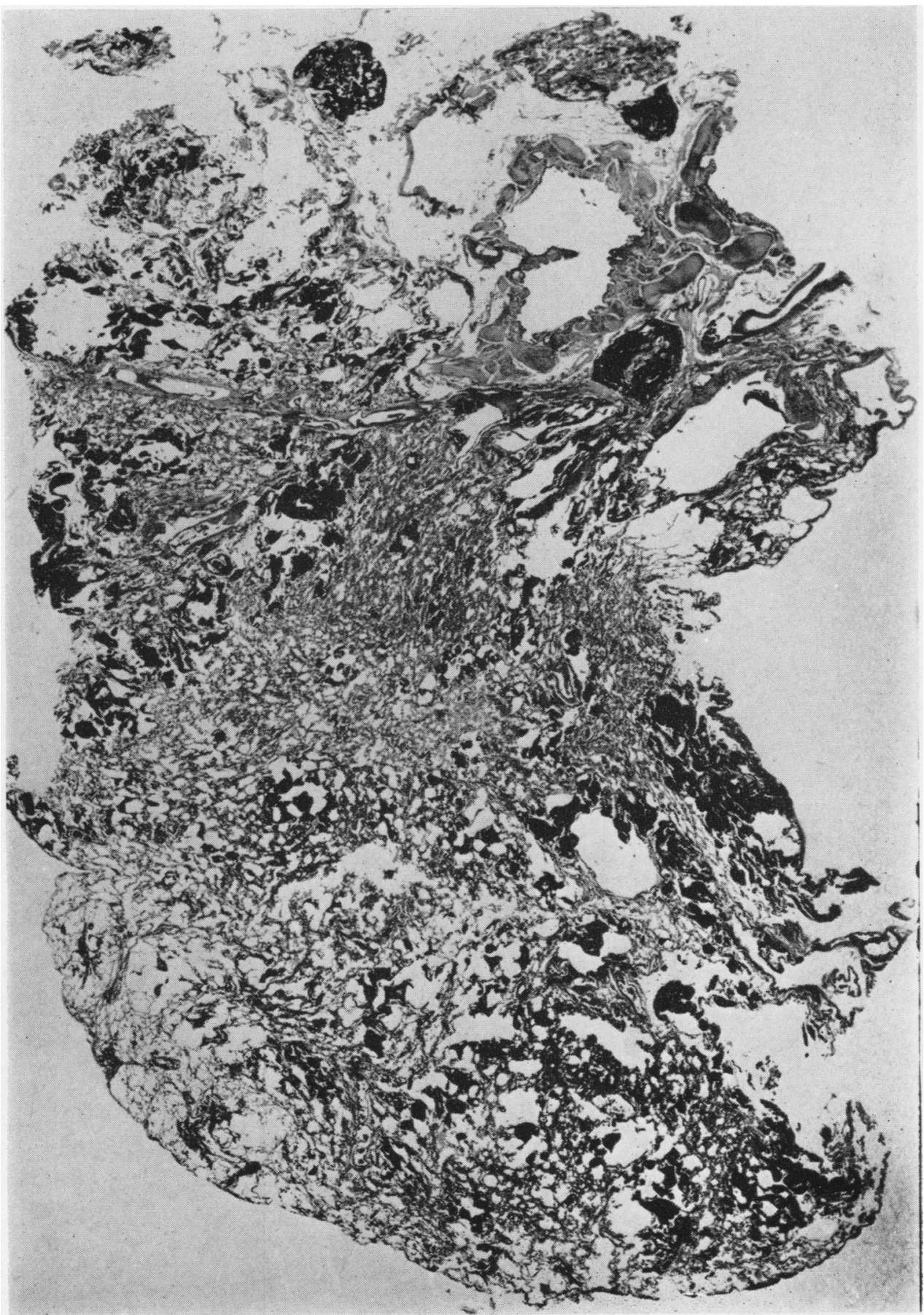

Fig. 4.-A large section of the left upper lobe in the perihilar region showing massive fibrosis characterized by densely pigmented thick collagenous strands and fibrous nodules: also widespread focal emphysema. Other areas show pigmented nodules, severe focal emphysema, and moderate fibrosis. (Van Gieson $\times$ 2.6.) 


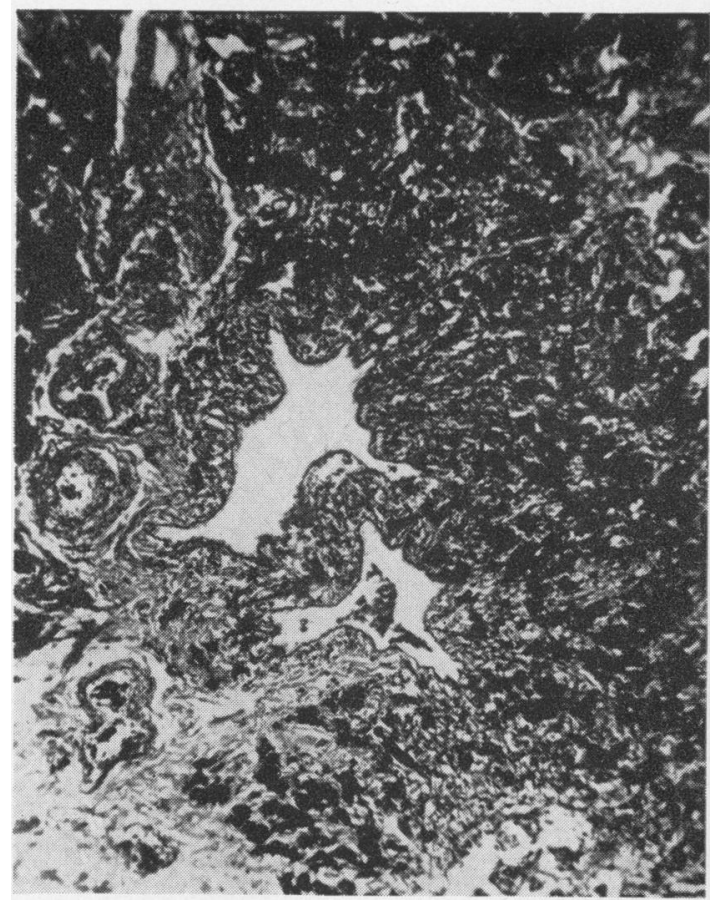

Fig. 5

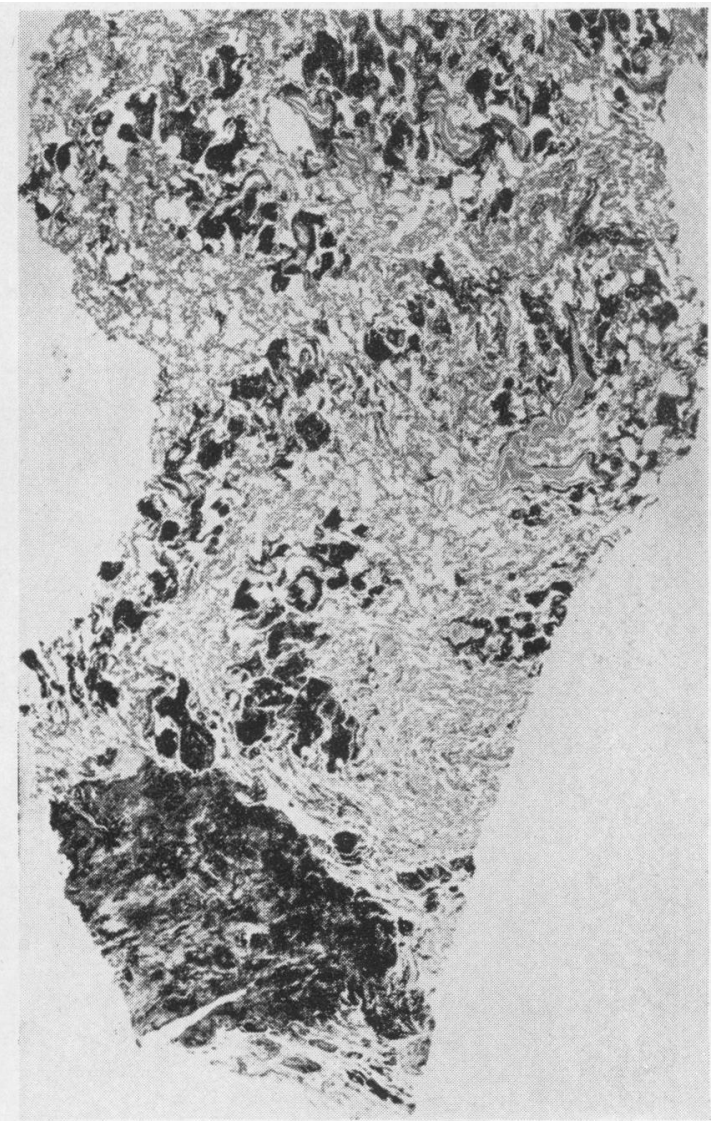

Fig. 6

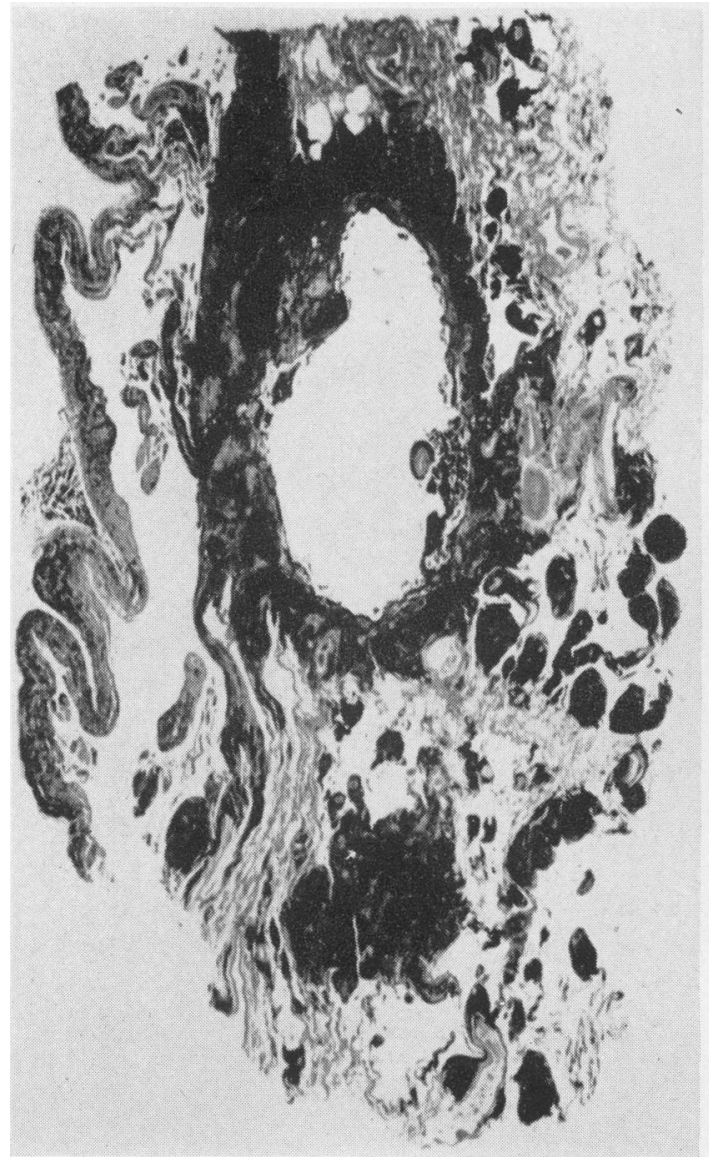

FIG. 5.-A lung field showing a dense mesh-work of coarse reticulin fibrils, surrounding blood vessels and bronchioles: also tangled pigment-laden collagen fibres. (Reticulin stain $\times 60$.)

FIG. 6.-In this section there are single and groups of pigment aggregates showing a tendency to coalesce to form larger collagenous nodules: the large nodule shows little resemblance to the typical silicotic lesion. (Haematoxylin and eosin $\times 7$.)

FIG. 7.-This illustrates a large liquefied nodule emptied of pigment sludge in the wall of a bronchus: also smaller nodules which show no softening. (Haematoxylin and eosin $\times 5$.)

FIG. 8 (opposite).-A large area of the right lower lobe showing much less marked fibrosis and emphysema; the appearances resemble simple pneumoconiosis. (Haematoxylin and eosin $\times 3.28$.)

FIG. 7 


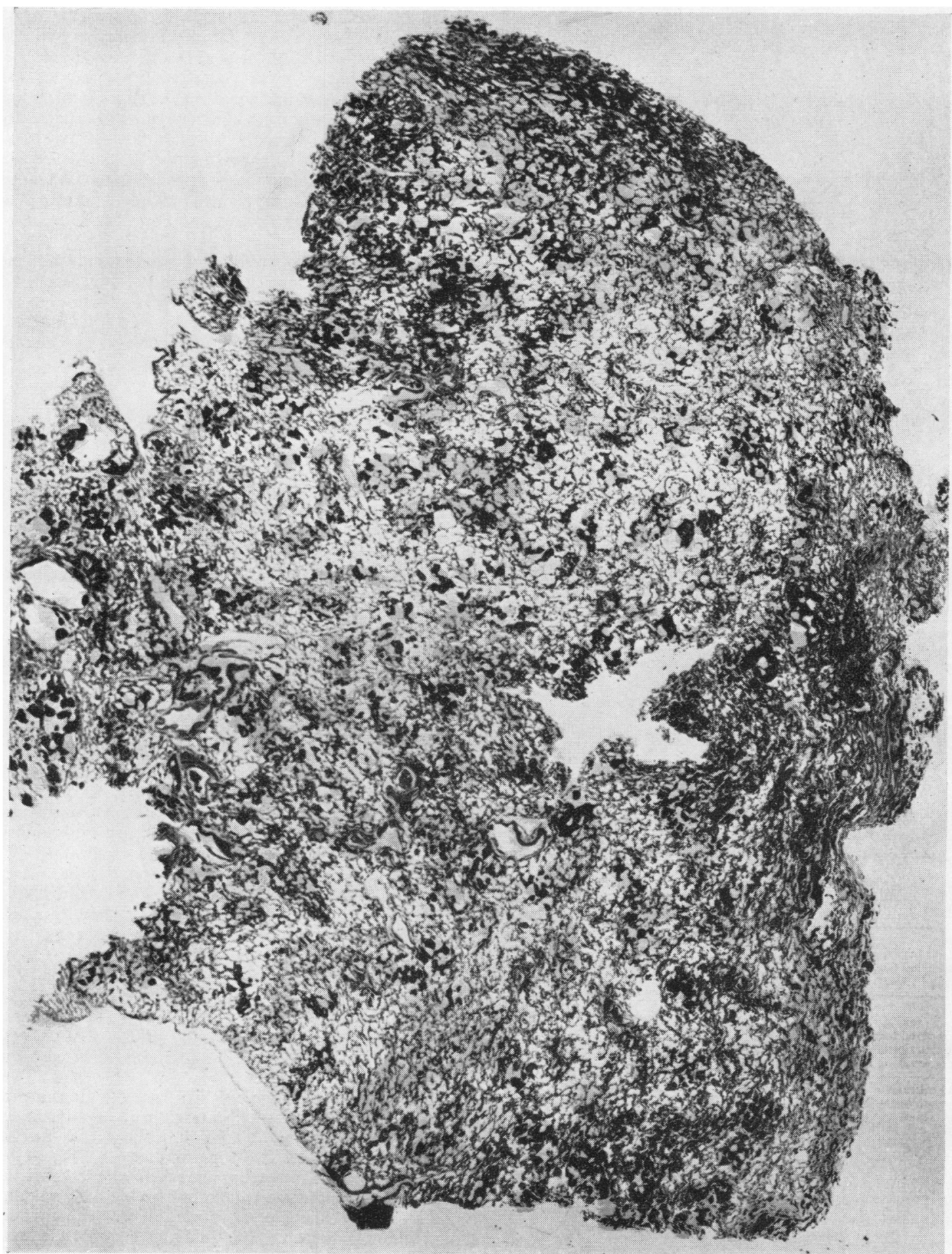




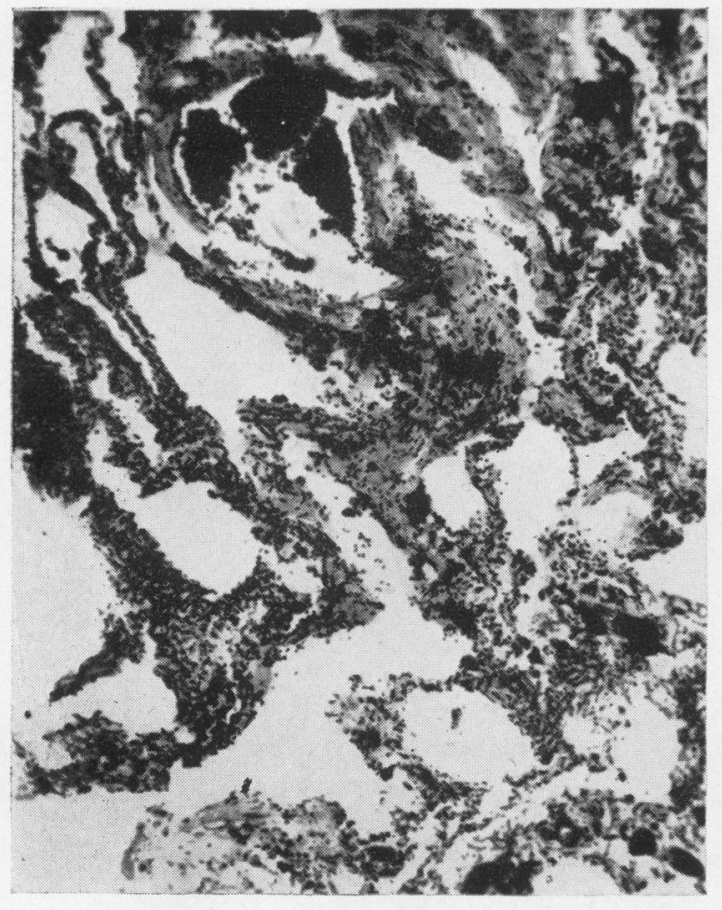

Fig. 9.-A field in the same lobe as Fig. 8, at a higher magnification showing very few pigment aggregates and only slight focal emphysema. (Lendrum's Melling Yellow $\times 63$.)

TABLE 1

DETERMINATIONS OF ASH AND QUALITATIVE SPECTROGRAPHIC ANALYSIS

\begin{tabular}{|c|c|c|c|c|c|}
\hline \multirow[b]{2}{*}{$\begin{array}{l}\text { A: } \\
\text { Ash (as \% weight } \\
\text { of dried formalin- } \\
\text { fixed tissue) }\end{array}$} & \multicolumn{2}{|c|}{$\begin{array}{c}\text { Case Reported } \\
\text { Here (A.W.) } \\
\text { (two samples) }\end{array}$} & \multicolumn{2}{|c|}{$\begin{array}{c}\text { Adult Male } \\
\text { Town Dweller }\end{array}$} & \multirow{2}{*}{$\begin{array}{c}\begin{array}{c}\text { Case of } \\
\text { Pneumoconiosis } \\
\text { in a Coal-miner }\end{array} \\
3 \cdot 147\end{array}$} \\
\hline & $1 \cdot 164$ & $1 \cdot 313$ & 0.865 & 0.990 & \\
\hline $\begin{array}{l}\text { B: } \\
\text { Ash (as \% weight } \\
\text { of dried formalin- } \\
\text { fixed tissue) after } \\
\text { removal of } \mathrm{NaCl}\end{array}$ & 0.427 & 0.450 & 0.275 & 0.289 & $2 \cdot 030$ \\
\hline 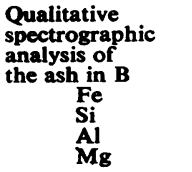 & $\begin{array}{l} \pm \\
\pm \\
-\end{array}$ & $\begin{array}{l}+ \\
\pm \\
\pm \\
\pm\end{array}$ & $\begin{array}{l} \pm \\
\pm \\
\equiv\end{array}$ & $\begin{array}{l}+ \\
\pm \\
\pm\end{array}$ & $\begin{array}{r}+ \\
+ \\
+ \\
+\end{array}$ \\
\hline
\end{tabular}

+++ Present in large amounts.

+ Present in small amounts.

\pm Present in trace amounts.

\pm Present in slight trace amounts. forming bands of dust impregnated collagenous tissue. Inside the alveoli there were numerous pigmented phagocytes similar to those seen in the bronchioles.

Vascular changes were conspicuous. Most of the smaller and many of the larger arteries showed thickened intima, in some instances the lumen was occluded by recanalized fibrous tissue. Portions of the internal elastic laminae along with neighbouring media and adventitia were necrotic and had been replaced by collagenous tissue densely infiltrated with black pigment; the appearances were similar to those described by Geever (1947).

When examined by polarized light numerous sections and samples of the lung dust showed no optical activity. Incinerated sections showed that most of the pigment was combustible and optical activity was not seen after heat and acid treatment. Some iron which was present in the incinerated sections was thought to be of haematogenous origin. An exhaustive search for asbestos bodies and the "curious bodies" found in talc pneumoconiosis (McLaughlin, Rogers, and Dunham, 1949) gave negative results. A large number of sections and numerous films made from the material in the liquefied nodules were examined for tuberculosis and also gave negative results.

Stomach: Small areas of gastric mucosa and submucosa were infiltrated with deposits of carbon black; many of the mucous glands which were peppered with the black dust appeared atrophied. The carbon had presumably been swallowed along with sputum.

Skin: Naked eye appearances suggested that the pigment had penetrated to the dermis but this was not confirmed by microscopical examination.

Carbon deposit was not found elsewhere in the body.

Physico-chemical Examination of Lungs and Lung Dust

A preliminary chemical examination of portions from the lungs of the deceased was made by Mr. A. Thompson and the results compared with a normal control and samples from a coal-miner with pneumoconiosis (Table 1). The samples of lung were dried at $105^{\circ} \mathrm{C}$. and then ashed (line A.). As the lungs had been fixed in formol-saline the salt was removed and the ash, as a percentage of the dried tissue, recalculated (line B). The ash, after removal of sodium chloride, was examined spectroscopically and gave the qualitative results shown.

This rough analysis suggested that the chemical composition varied throughout the lung and that the lesion was chemically markedly different from the pneumoconiosis found in coal-miners when siliceous rock had been encountered.

The deposit which was washed from the lungs during histological fixation was purified and examined by electron microscopy (National College of Rubber Technology) with the following results:

" The specimen shows the presence of spherical particles which form agglomerates and chains giving an appearance typical of the behaviour of carbon black. The approximate particle diameter of 0.1 microns being of the order found in fine thermal black." 


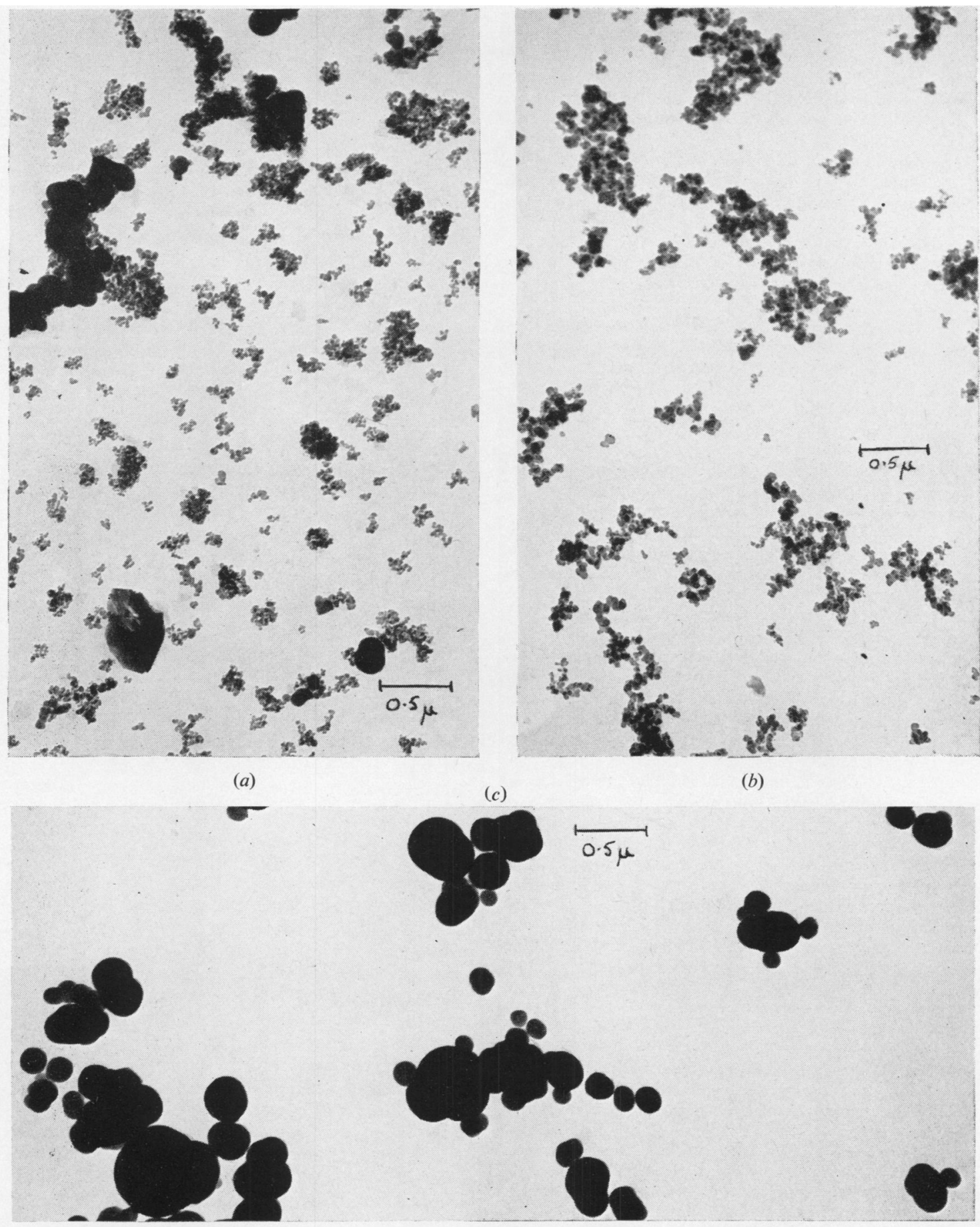

Fig. 10.-(a) Electron micrographs of lung dust $\times 21,000$. There are two components, very fine and coarser particles which are similar to the forms of carbon black with which A.W. had worked. The very fine particles are similar to furnace black $(b)$ and the coarser particles to thermal black $(c)$. 
As these preliminary examinations had proved interesting, it was thought that a more detailed examination should be made and this was undertaken by Dr. Nagelschmidt of the Safety in Mines Research Establishment in Sheffield.

Samples from various parts of the lungs were dried, ground, and treated with concentrated bydrogen peroxide to isolate the dust. The dust amounted to $15 \%$ of the dried lungs: $90 \%$ of the dust was carbon and $10 \%$ ash. The ash, which had been obtained at $450^{\circ} \mathrm{C}$., contained $27 \% \mathrm{SiO}_{2}$ and $10 \% \mathrm{Fe}_{2} \mathrm{O}_{3}$ : its ignition loss at $850^{\circ} \mathrm{C}$. was $7.5 \%$.

$X$-ray diffraction analysis of the ash showed a little mullite and talc with doubtful traces of quartz and cristobalite.

Electron microscopy showed two main components (Fig. 10a). The finer particles $(20 / 30 \mathrm{~m} \mu$ in diameter) were similar to furnace and channel blacks: the coarser particles $(200 / 400 \mathrm{~m} \mu)$ were similar to thermal black. The samples used for comparison were of the types with which he had worked (Figs. $10 \mathrm{~b}, \mathrm{c}$ ).

Carbon Black. - Carbon black, in the sense in which we use it, includes all forms of carbon prepared by the channel, furnace, lampblack, and thermal processes: these carbons are chemically distinct from bone-black, charcoal, and chimney soot. Graphite differs in that it is crystalline and, in the natural state as mined, contains up to $25 \%$ of siliceous material by weight.

Chemically, carbon blacks are essentially carbon combined with hydrogen and oxygen. The hydrogen derives from the hydrocarbon used in manufacture and is thought to be attached to the carbon atoms by true valency bonds giving an unsaturated condition. The chemisorbed oxygen affects the hydrophilic properties of the black and these properties are of importance to the rubber industry. There are various other contaminants in carbon used commercially; these depend on the hydrocarbon source and the method of manufacture: they include various volatile benzenesoluble substances, iron oxides from the channels or pipes and calcium salts from the quenching water used in manufacture. The ash content is usually less than $0.1 \%$ but some furnace blacks may have up to $1 \%$ ash, which is mainly iron oxides. Silica oxides are present in very small amounts or not at all. Samples of channel and furnace blacks, which we checked, gave ash values of 0.038 and $0.047 \%$ : the ash contained iron and calcium compounds; silica was not detected.

The rubber works concerned in this case uses large amounts of furnace and channel blacks with very small amounts of lamp and acetylene blacks. The carbon is used as a reinforcing filler, its main effect. being to increase stiffness, modify tensile and tear strengths, and increase abrasion resistance. Stiffness is proportional to the absolute amount of filler added: tensile strength increases as particle size decreases, abrasion resistance is generally dependent on particle size but different methods of carbon manufacture have some effect. The particle size of the carbon used in the rubber industry is generally in the range of 20 to $500 \mathrm{~m} \mu$. Owing to the small particle size required in rubber manufacture it is obvious that fine carbon dust will always be a problem in rubber works.

\section{Discussion}

This case raises matters of considerable importance in the aetiology of pneumoconiosis. The radiological and pathological findings were those of progressive massive fibrosis and resembled the advanced stage of coal-workers' pneumoconiosis with dense collagenous fibrosis and "infective nodules " in the upper parts of the lungs. The man had been exposed to carbon black for the greater part of his working life: 21 years were spent in the carbon black store where the dust concentration was very high. There had been no occupational risk in any other employment. The most likely explanation of the massive pulmonary fibrosis appears to be the combined action of carbon black and tuberculosis. Pulmonary tuberculosis in youth or middle age cannot be excluded owing to inadequate information and lack of bacteriological investigation. In fact, the history of a persistent cough, with sputum for many years, together with the presence of spinal and probably pulmonary tuberculosis in his wife some years after they were married, strongly suggests that he may have been infected.

In 1956 and 1958, when the patient was well over 60 , the clinical and radiological examinations of his chest were negative for active tuberculosis, the probable infection having died out. At necropsy, when the deceased was aged 65 , the usual microscopical and animal tests for tubercle were not done because the clinical data were not available. In the histological preparations of the lung tissues and in the sludge from the liquefied nodules Tubercle bacilli could not be demonstrated microscopically.

Another interesting feature in this case is the development of pneumoconiosis in the virtual absence of quartz: this is not entirely new. In his radiological examinations of carbon electrode workers, Koelsch (1952) suggested that carbon alone could cause proliferative changes in lungs and that carbon deposits could produce local circulatory disturbance and thus give rise to induration. The carbon or anthracite which they handled contained less than $1 \%$ of ash, including small amounts $(0.001$ to $0.003 \%)$ of silica, mostly in the form of silicate. He found advanced stages of pneumoconiosis with nodulation and conglomerate shadows. There was no pathological examination in any of his cases.

More recently, Watson (quoted by Gough, 1959) investigated the case of a man making carbon electrodes who was exposed to the dust of anthracite 
and coke. The changes in his lungs were indistinguishable from the massive fibrosis of coal-miners, yet these lungs, on careful analysis by Nagelschmidt, revealed very little quartz. Tubercle bacilli were grown from the lungs although the usual histological evidence of tuberculosis was lacking. There was simply the necrosis, which one often sees in coal-miners' lungs, which is due to the action of Tubercle bacilli but is unaccompanied by the usual endothelial and giant cell reaction.

During the chemical analysis it was noted that the burning characteristics of the carbon recovered from the lungs were different from those exhibited by the carbon to which the man was exposed. This was probably due to alteration of the hydrogen, oxygen, and volatile components by the physiological processes of the lungs.

It was also noted that areas of lung tissue, mainly in the lower lobes, suggested the appearances of simple pneumoconiosis without the additional effect of probable tuberculosis: there were few nodules, less marked emphysema, and minimal fibrogenic effect. That a relatively inert dust, such as carbon black, which contains very little free silica, can produce simple pneumoconiosis is now well recognized (Fletcher, 1952) and appears to bear some relation to pneumoconiosis due to inhalation of soot. The main differences between carbon black and soot are the smaller particle size of the former and the lesser surface adsorbed contamination with volatile organic matter. In cases of soot pneumoconiosis Gärtner and Brauss (1951) found that heavy exposure to soot inhalation could continue for many years before pneumoconiotic effects were seen on radiological examination. There is no pathology in any of the cases reported.

In the case under consideration prolonged exposure to heavy clouds of carbon was required to produce this degree of pneumoconiosis. It is also noteworthy that none of the other workers in the same factory, one of whom was employed in the carbon black store for 11 years, has developed pneumoconiosis. The study of this case suggests that carbon pneumoconiosis, whether simple or "infective", requires prolonged exposure to a heavy concentration of inert dust unless the workman happens to be allergic to the carbon or the organic contaminants which it bears.

We are indebted to H.M. Coroner for permission to publish this case: to Professor J. Gough for reviewing the histological findings and referring us to the literature: to Professor A. L. Cochrane for his opinion on the chest radiographs: to Dr. A. Meiklejohn for helpful advice: to Dr. A. T. Doig for most helpful reviews of the pathological and radiological appearances: to $\mathbf{M r}$. A. Thompson of the N.W. Forensic Science Laboratory, Preston, for chemical analysis: to Dr. G. Nagelschmidt of the Safety in Mines Research Establishment, Sheffield, for chemical and $x$-ray diffraction analysis and, together with the National College of Rubber Technology, for electron microscopy: to Dr. M. R. Geake for access to radiographs and medical history: to Messrs. J. H. Wilkinson and $\mathbf{J}$. Urquhart for technical assistance.

\section{REFERENCES}

Fletcher, C. M. (1952). Beitr. Silikose-Forsch. (1951), $10,119$. Gärtner, H., and Brauss, F. W. (1951). Med. Welt, 20, 252. Abstracted in Brit. J. industr. Med., 9, 238 (1952).

Geever, E. F. (1947). Amer. J. med. Sci., 214, 292.

Gough, J. (1947). Occup. Med., 4, 86.

(1959). In Modern Trends in Pathology, ed. D. H. Collins. p. 285, Butterworth, London.

International Labour Organization (1953). Third International Conference of Experts on Pneumoconiosis, Sydney, 1950. International Labour Office, Geneva.

Koelsch, W. (1952). Beitr. Silikose-Forsch. (1951) 10,162

Lochtkemper, F. I., and Teleky, L. (1932). Arch. Gewerbepath. Gewerbehyg, $3,418,600,673,712$.

McLaughlin, A. I. G., Rogers, E., and Dunham, K. C. (1949). Brit. J. industr. Med., 6, 184

Meiklejohn, A. (1956). In Industrial Medicine and Hygiene, ed. E. R. A. Mereweather, Vol. 3, p. 103. Butterworth, London. 1957). In Reports, 12th International Congress on Occupational Health, Helsinki, 1957, Vol. 3, p. 335.

Vaccarrezza, R. F. (1958). Proc. of Vth Int. Congr. on Diseases of the Chest, Tokyo, 1958, Abstracts of Papers, p. 163. 